\title{
Infection kinetics of human adenovirus serotype 41 in HEK 293 cells
}

\author{
Joselma Siqueira-Silva', Fernanda Perez Yeda', Anne-Laure Favier², Paulette Mezin ${ }^{3}$, \\ Misael Leonardo Silva', Karina Médici Barrella1, Dolores Úrsula Mehnert', Pascal Fender², \\ Charlotte Marianna Hársi ${ }^{1 /+}$
}

\begin{abstract}
${ }^{1}$ Laboratório de Biologia Molecular de Adenovírus, Departamento de Microbiologia, Instituto de Ciências Biomédicas, Universidade de São Paulo, Av. Prof. Lineu Prestes 1374, Edifício Biomédicas 2 sala 229, 05508-900 São Paulo, SP, Brasil ${ }^{2}$ Institut de Biologie Structurale Jean-Pierre Ebel, Grenoble, France ${ }^{3}$ Centre Hospitalier Universitaire de Genoble, La Tronche, France
\end{abstract}

The purpose of this work was to acquire an overview of the infectious cycle of HAdV-41 in permissive HEK 293 cells and compare it to that observed with the prototype of the genus, Human adenovirus C HAdV-2. HEK 293 cells were infected with each virus separately and were harvested every $12 \mathrm{~h}$ for seven days. Infection kinetics were analysed using confocal and electronic microscopy. The results show that, when properly cultivated, HAdV-41 was not fastidious. It had a longer multiplication cycle, which resulted in the release of complete viral particles and viral stocks reached high titres. After $60 \mathrm{~h}$ of infection, the export of viral proteins from the infected cell to the extracellular milieu was observed, with a pattern similar to that previously described for HAdV-2 penton-base trafficking after $30 \mathrm{~h}$ of infection. HAdV-41 had a non-lytic cycle and the infection spread from the first infected cell to its neighbours. The release process of the viral particles is unknown. The results observed for HAdV-41 infection in HEK 293 cells show how different this virus is from the prototype HAdV-2 and provides information for the development of this vector for use in gene therapy.

Key words: Human adenovirus F - infection kinetics - virus cultivation - confocal microscopy - electronic microscopy

Human adenoviruses are members of the Adenoviridae family Mastadenovirus genus and include 51 serotypes, which are classified into six different species (from A to F) according to their biological and molecular properties. Characteristic features of each species determine cell tropism and pathogenesis, which can result in ocular, respiratory, enteric and urinary tract infections (Cusack 2005, Short et al. 2006). All adenoviruses are non-enveloped, double-stranded DNA viruses. The icosahedral virions, of approximately $90 \mathrm{~nm}$ in diameter, have 240 copies of trimeric hexons on the facets and a penton complex, composed of a pentameric base and an antenna-like trimeric fibre, at each of the 12 vertices. Both proteins are involved in host-cell recognition and in the initial steps of cell infection (Bergelson 1999, Coyne \& Bergelson 2005).

Despite the variety of adenovirus serotypes, the data describing the virus multiplication cycle and intracellular trafficking have been obtained largely from studies of the serotypes HAdV-2 and HAdV-5, which are both members of the Human adenovirus $C$ species. The host cell is recognised in two steps: the C-terminal globular domain of the fibre binds to the Coxsackie-Adenovirus Receptor (CAR) (Bergelson et al. 1997) and the pentonbase, through its RGD (Arg-Gly-Asp) motif, subsequently interacts with the $\alpha v \beta 3$ and $\alpha v \beta 5$ integrins inserted in the cell membrane, resulting in the internalisation of the

Financial support: FAPESP (00/00176-1), (02/13859-5, JSS), CNPqCNRS (910078/99-8)

+ Corresponding author: chmharsi@icb.usp.br

Received 3 December 2008

Accepted 13 May 2009 viral particle via receptor-mediated endocytosis (Mathias et al. 1994, Bergelson et al. 1997, Meier \& Greber 2003, Coyne \& Bergelson 2005). Upon acidification of the endosome, integrins and the penton-base assist in releasing the virus from the early endosome into the cytosol. The adenovirus capsid then interacts with motor proteins and is transported over microtubules toward the nucleus, where the DNA is delivered and replicated (Greber et al. 1993, 1997, Wickham et al. 1994). Newly synthesised viral proteins are carried into the nucleus and the virus progeny are assembled. Release of the virus from infected cells occurs through cell lysis.

Given the similarity in the structure of the adenovirus capsid across the genus, one might assume that the pathways of penetration, intracellular trafficking and release of any member will be representative of the group. However, this model of viral multiplication cannot be applied to all adenovirus species. Human adenovirus B uses CD46, a protein involved in complement binding, as a primary receptor (Gaggar et al. 2003). After internalisation via endocytosis, Human adenovirus $B$ accumulates and has a long residence time inside endosomal compartments until it reaches late endosomes or lysosomes (Miyazawa et al. 2001). Release of capsids into the cytosol occurs in a lower $\mathrm{pH}$ environment than that of species $\mathrm{C}$ adenoviruses and is followed by rapid cytosolic translocation to the nucleus through an unknown mechanism (Mautner et al. 1989). Fibre protein is known to influence membrane lysis and intracellular trafficking. For example, chimeras of species $C$ viruses carrying species B fibres show delayed intracellular trafficking (Miyazawa et al. 1999).

Serotypes 40 and 41 of Human adenovirus F (HAdV40 and HAdV-41) have attracted considerable attention in recent years. These serotypes are important etiologi- 
cal agents of infantile gastroenteritis (Uhnoo et al. 1984) and apparently do not cause disease outside of the gastrointestinal tract, which make them attractive as vectors for therapy or vaccination. The molecular basis of their specific pathogenesis is not known, but may be related to their capsid structures. HAdV-40 and HAdV-41 have unique structural features relative to other human adenoviruses. The virions contain two different fibres (a long and a short one) that are encoded by separate genes (Pieniazek et al. 1990, Kidd et al. 1993) and are distributed in an equimolar ratio (1 per penton-base) on the particle (Pieniazek et al. 1990, Favier et al. 2002). The long fibre of HAdV-41 recognises CAR with a lower affinity than that of HAdV-2 (Roelvink et al. 1998). The short fibre does not have a known receptor and its function in the infection process has not yet been determined. Another structural difference of these serotypes is the lack of the RGD motif (Arg-Gly-Asp) on the penton-base. Instead, the HAdV-40 penton-base has an RGAD (Arg-Gly-AlaAsp) motif and the HAdV-41 has an IGDD (Ile-GlyAsp-Asp) motif (Albinson \& Kidd 1999). The cellular proteins that interact with the penton-bases of Human adenovirus $F$ are unknown.

Human adenovirus $F$ species replicate quite well in the intestinal epithelia (Uhnoo et al. 1984, Tiemessen et al. 1993). However, these viruses have been considered fastidious in culture (Kidd \& Madeley 1981, Brown et al. 1984, Tiemessen \& Kidd 1990). HAdV-40 and HAdV-41 have the ability to replicate in different cell lines, such as HEK 293 (Takiff et al. 1981, Chiba et al. 1983, Uhnoo et al. 1983, Brown \& Petric 1986, Mautner 2007) and KB cells (Witt \& Bousquet 1988, Mautner et al. 1989). Some authors suggest that the permissiveness of the HEK 293 cell line to infection by HAdV-41 is a result of the basal expression of HAdV-5's E1A region, which may complement the defective function of HAdV-4l's E1A region (Takiff et al. 1981). Others suggest that E1A-like cellular factors such as Hsp70, which are only present in continuous cell lines, could complement the E1A function of these adenoviruses (Pieniazek et al. 1990). In contrast, it was also observed that the expression of HAdV-41's E1A proteins, considered defective by some authors, is in fact effective in infected cells. Furthermore, the expressed products were able to trans-activate E1A-deleted HAdV-5 mutants (Croyle et al. 1998). The HEK 293 cell line is considered permissive to infection by HAdV-41 and has more recently been used to produce therapy vectors (Lemiale et al. 2007). However, an efficient culture of this virus in this cell line, with recovery of complete viral particles, is only obtained when special cultivation procedures, such as maintenance in a medium with low FBS concentration $(0.2 \%)$, are used (Pieniazek et al. 1990).

This study describes the progression of the infection cycle of HAdV-41 in HEK 293 cells, a permissive cell type used for gene therapy vector production. The findings are compared to those obtained with the prototype HAdV-2.

\section{MATERIALS AND METHODS}

Virus prototypes and cell cultures - The cell cultures, anti-sera and adenovirus prototype strains used in this study belong to the virus and cultures collection of our laboratory and have been collected over the years from reference laboratories. The HAdV-41 Tak strain was donated by Dr. RI Glass, previously of the Centers for Disease Control, Atlanta, GA, USA. The HEK 293 cells (human embryonic primary kidney cells transformed with sheared HAdV-5 DNA) were obtained directly from Dr. FL Graham, Department of Pathology and Molecular Medicine, McMaster University, Hamilton, Ontario, Canada (Graham et al. 1977). The HAdV-2 prototype and HEp2 cells (human epidermoid carcinoma of the larynx) were obtained from Dr. HG Pereira, then at the Central Public Health Laboratory in London, UK. The rabbit hyperimmune serum against HAdV-5 was prepared as described previously (Peret et al. 1995).

Cell culture - The HEK 293 cells were cultured in a monolayer with Eagle's Minimum Essential Medium (EMEM) supplemented with $10 \%$ of foetal bovine serum (FBS), both from Cultilab, Emcare, Campinas, Brazil. The cultures were split 1:3 every seven days, dispersed with a $0.25 \%$ trypsin solution in Dulbecco's phosphatebuffered saline, pH 7.4 (PBS) and suspended in EMEM with $10 \%$ FBS.

The HEp-2 cells were cultivated in EMEM with 10\% FBS, split 1:5 once a week and dispersed with $0.25 \%$ trypsin supplemented with $0.5 \%$ ethylenediaminetetraacetic acid (EDTA) in PBS. The cultures were maintained at $37^{\circ} \mathrm{C}$ in a $5 \% \mathrm{CO}_{2}$ atmosphere.

Virus strains - The HAdV-41 strain was cultivated in HEK 293 cells. Monolayers were prepared in $75 \mathrm{~cm}^{2}$ vessels (Nunc ${ }^{\mathrm{TM}}$, Thermo Fisher Scientific, Waltham, MA) seeded with $4 \times 10^{6}$ cells. After $48 \mathrm{~h}$, when the cells had reached $70 \%$ confluence, the cells were washed with PBS ( $\mathrm{pH}$ 7.4) supplemented with $1 \mathrm{mM}$ of $\mathrm{CaCl}_{2}$ and $1 \mathrm{mM}$ of $\mathrm{MgCl}_{2}$ (PBS-A). The cells were then inoculated with a 0.1 MOI HAdV-41 stock suspension. After an adsorption period of $2 \mathrm{~h}$ at $37^{\circ} \mathrm{C}$, the vessels were filled with EMEM supplemented with $0.2 \%$ FBS (Pieniazek et al. 1990). The inoculated cultures were observed daily until a cytopathic effect was evident (7-10 days). After three cycles of freezing and thawing, subsequent subcultures of HAdV41 were prepared from the infected cells. HAdV-41 stock suspensions were prepared from the seventh passage in culture. Infected cells were harvested together with the culture medium and submitted to three cycles of freezing and thawing. The viral suspension was clarified by adding an equal volume of Vertrel-XF $(1,1,1,2,3,4,4,5,5,5,5,5$-decafluoropentane, Clarus Technology ${ }^{\circledR}$, Hortolândia, São Paulo), followed by vigorous vortexing and centrifugation at $3,000 \mathrm{~g}$ for $20 \mathrm{~min}$. HAdV-2 was cultivated in vessels seeded with $2 \times 10^{6} \mathrm{HEp}-2$ cells. A stock suspension was prepared after the fifth passage in culture using the procedure described above.

Virus production and purification in $\mathrm{CsCl}$ Gradient - Monolayers of HEK 293 cells were prepared in twelve $185 \mathrm{~cm}^{2}$ vessels ( $\mathrm{Nunc}^{\mathrm{TM}}$ ). After two or three days, when cell culture confluence had reached $70 \%$, the cells were washed with PBS-A and the cultures were inoculated with a 0.1 MOI seventh passage HAdV-41 stock suspension. After an adsorption period of $2 \mathrm{~h}$ at $37^{\circ} \mathrm{C}$, each 
culture was filled with EMEM supplemented with $0.2 \%$ FBS. Inoculated HEK 293 cells were incubated at $37^{\circ} \mathrm{C}$ in a $5 \% \mathrm{CO}_{2}$ atmosphere and observed daily. When the cytopathic effect was evident (between 7-10 days), the cells were harvested and centrifuged at $220 \mathrm{~g}$ for $10 \mathrm{~min}$. The supernatants were then removed and the cell pellets were stored at $-20^{\circ} \mathrm{C}$. HAdV-2 was cultivated in twelve $185 \mathrm{~cm}^{2}$ vessels seeded with HEp-2 cells. Infected cells were collected 4-5 days after inoculation.

HAdV-41 and HAdV-2 were purified in $\mathrm{CsCl}$ gradients prepared in $10 \mathrm{mM}$ HEPES buffer at $\mathrm{pH}$ 7.4. Viruses were released from the infected cell pellets after three cycles of freezing and thawing. Cells were suspended in a $10 \mathrm{mM}$ HEPES buffer at $\mathrm{pH}$ 7.4. Suspensions were clarified by adding an equal volume of Vertrel XF (Clarus Technology), followed by vigorous vortexing. Cell debris was removed by centrifugation at 2,619 $g$ for 25 $\min$ at $4{ }^{\circ} \mathrm{C}$. Viral particles in the supernatant were purified in $\mathrm{CsCl}$ gradients prepared in a $10 \mathrm{mM}$ HEPES buffer at $\mathrm{pH}$ 7.4, following a previously described protocol (Kanegae et al. 1994). Purified HAdV-41 and HAdV-2 were stored at $-20^{\circ} \mathrm{C}$. A portion of the purified HAdV-41 was applied to a clean side of carbon on mica grid (carbo/ mica interface) and negatively stained with uranyl acetate. Micrographs were taken under low-dose conditions with a Philips CM12 transmission electronic microscope (TEM, Philips, Eindhoven, Netherlands) operated at 80 $\mathrm{kV}$ and a nominal magnification of 15,000 times.

Polyclonal antibody production - The hyperimmune serum against HAdV-41 was prepared in a two-month-old New Zealand rabbit inoculated subcutaneously with 200 $\mu \mathrm{L}$ of purified HAdV-41 mixed with an equal volume of incomplete Freund's adjuvant (Sigma Immunochemicals, USA). The first three inoculations were repeated at 15-day intervals and the booster was given six months later. Ten days after the booster, the animal was bled under 3\% pentobarbital anaesthesia. The animal experimental protocol was previously approved by the Committee on Ethical Experimentation in Animals of the Institute of Biomedical Sciences of the University of São Paulo (116/2002).

The hyperimmune serum was separated by centrifugation and titred using the ELISA method. A 96well microplate (TPP ${ }^{\circledR}$, Trasadingen, Switzerland) was coated with monoclonal antibodies, diluted 1:6,400 in a carbonate-bicarbonate buffer at $\mathrm{pH} 9.5$, against HAdV41 hexon protein (Wood et al. 1989). As an antigen, 100 $\mu \mathrm{L}$ of the clarified HAdV-41 stock suspension, diluted $1: 64$ in PBS pH 7.4 with $0.5 \%$ Tween $^{\circledR} 20$ and $5 \%$ of dry milk $(\mathrm{PBS} / \mathrm{T} / \mathrm{M})$, was added to each well and left for $16 \mathrm{~h}$ at $4^{\circ} \mathrm{C}$. Serial two-fold dilutions $(100 \mu \mathrm{L})$ of the rabbit hyperimmune serum anti-HAdV-41, prepared in PBS/T/M from 1:200-1:10,240, were added to each well in duplicate. Antibodies were detected with goat antirabbit IgG serum labelled with horseradish peroxidase (Gibco, BRL, USA) diluted 1:6,400 in PBS/T/M. Between each step, the microplate was washed three times with PBS/T and decanted. The reaction was visualised via the addition of $100 \mu \mathrm{L}$ substrate solution to each well $\left(0.1 \mathrm{M}\right.$ citrate buffer, $0.2 \mathrm{M} \mathrm{Na}_{2} \mathrm{HPO}_{4}, \mathrm{H}_{2} \mathrm{O}_{2}$ and O-phenylenediamine dichloride, Sigma, USA) and read in a spectrophotometer with a $496 \mathrm{~nm}$ filter.
Cross-titration by indirect immunofluorescence assay (IIF) of rabbit anti-HAdV-41 and anti HAdV-5 polyclonal sera against virus infected cells - A 96-well microplate $\left(\mathrm{TPP}^{\circledR}\right)$ was coated with HEK 293 cells $(20,000$ cells/well) prepared in EMEM with 10\% FBS. Before inoculation, the culture medium was gently decanted and the cells were washed with PBS-A. Two-fold dilutions of the HAdV-41 stock suspension (from 1:2-1:1024) were prepared in EMEM and distributed in 10 columns of the plate, eight wells per dilution $(25 \mu \mathrm{L}$ each). The last two columns were not inoculated and were used as negative controls. After $2 \mathrm{~h}$ of incubation, the wells were filled with $100 \mu \mathrm{L}$ of EMEM supplemented with $0.2 \%$ FBS. After $48 \mathrm{~h}$ of incubation, the cultures were washed with PBS ( $\mathrm{pH}$ 7.4) and the cells were fixed with absolute methanol at $-20^{\circ} \mathrm{C}$ (MERCK).

Rabbit anti-HAdV-41 serum was diluted in PBS, $\mathrm{pH}$ 7.2 (2-fold dilutions, from 1:80-1:2,560). Each dilution was distributed in one row of the plate: 10 wells with infected cells and two with non-infected cells $(50 \mu \mathrm{L}$ per well). The rabbit pre-immune serum was diluted 1:160 and 1:320 and was distributed in the last two rows of the plate. The reaction was incubated for $1 \mathrm{~h}$ at $37^{\circ} \mathrm{C}$. The cultures were gently washed three times with PBS, pH 7.2. Goat anti-rabbit gamma globulin (IgG) serum labelled with fluorescein (PIERCE, USA) was diluted 1:100 in PBS, pH 7.2, with Evan's Blue (MERCK) and distributed $(100 \mu \mathrm{L})$ to each well. The reaction was incubated for $1 \mathrm{~h}$ at $37^{\circ} \mathrm{C}$ and the cultures were washed three times with PBS, pH 7.2. To enhance fluorescence, a drop of $90 \%$ glycerol diluted in carbonate-bicarbonate buffer (pH 9.5) was added to each well and the excess was decanted. The microplate was analysed using an immunofluorescence microscope (Leica DMLS, Germany).

The same procedure of cross-titration was performed in another plate inoculated with HAdV-2 stock suspension and the rabbit anti-HAdV-5 serum. Since HAdV-2 and HAdV-5 belong to the same species and cross react, the HAdV-5 anti-serum was very good at revealing cells infected with HAdV-2. Anti-sera titres were determined as the reverse of the highest dilution where fluorescent infected cells could be unequivocally distinguished without background and where negative controls showed no fluorescence.

To remove non-specific antibodies before titration, anti-HAdV-41 and anti-HAdV-5 sera were absorbed with fresh HEK 293 cell pellets (incubated for $1 \mathrm{~h}$ at $37^{\circ} \mathrm{C}$ and centrifuged for $800 \mathrm{~g} / 15 \mathrm{~min}$ ) and HEK 293 cell protein powder extracted with acetone.

Purified virus titration (HAdV-2 and HAdV-41) by $I I F$ - The HEK 293 cells were cultivated in a 96-well microplate $(20,000$ cells/well), washed with PBS-A and inoculated, in duplicate, with serial two-fold dilutions (from 1:2-1:1,024) of the purified HAdV-2 and HAdV-41 viruses. After $48 \mathrm{~h}$, infected cells were washed with PBS (pH 7.4) and fixed with two drops of methanol (MERCK). Viral proteins were detected by adding anti-sera [anti-HAdV-5 (1:2,000) and anti-HAdV-41 (1:800)] diluted in PBS, pH 7.2. Infected cells were revealed with 100 $\mu \mathrm{L}$ goat anti-rabbit IgG serum labelled with fluorescein 
(PIERCE, USA) diluted to 1:100 in PBS (pH 7.2) with Evan's Blue (MERCK). Viral titres were determined as fluorescent focus units (FFU/mL).

$H A d V-2$ and $H A d V-41$ viral infection kinetics - Two 24-well microplates $\left(\mathrm{TPP}^{\circledR}\right)$ containing coverslips $(13 \mathrm{~mm}$ diameter) covered with poly-D-lysine (SIGMA, USA) were seeded with HEK 293 cells prepared in EMEM supplemented with $10 \%$ FBS (50,000 cells per coverslip). After two days, the cultures were inoculated with 0.04 MOI of one of the purified viruses diluted in EMEM. Two hours later, the wells were filled with $500 \mu \mathrm{L}$ of EMEM with $0.2 \% \mathrm{FBS}$. Cultures were incubated at $37^{\circ} \mathrm{C}$ in a $5 \% \mathrm{CO}_{2}$ atmosphere. The coverslips were harvested during a period of seven days at $12 \mathrm{~h}$ intervals. A third of the 24-well microplate with coverslips seeded with HEK 293 cells was mock infected with EMEM and used as a control. The control cells were harvested at the same intervals. The cells were fixed with methanol at $-20^{\circ} \mathrm{C}$ and the coverslips were stored at $-20^{\circ} \mathrm{C}$ until the next step.

The anti-HAdV-41 and anti-HAdV-5 sera were diluted 1:800 and 1:2000, respectively, in PBS (pH 7.2), whereupon $500 \mu \mathrm{L}$ of each dilution was added to a respective coverslip, including negative controls. The cultures were incubated for $1 \mathrm{~h}$ at $37^{\circ} \mathrm{C}$ and washed three times with PBS (pH 7.2). Subsequently, $500 \mu \mathrm{L}$ of fluoresceinconjugated serum diluted to 1:100 in PBS (pH 7.2) with Evan's Blue was added to each well. The cultures were incubated for $1 \mathrm{~h}$ at $37^{\circ} \mathrm{C}$ and washed three times with PBS, pH 7.2. Coverslips were mounted over microscope slides with glycerol in a carbonate-bicarbonate buffer at pH 9.5. Cells were visualised with a Zeiss LSM 510 confocal microscope (Carl Zeiss GmbH, Germany) using a pinhole setting corresponding to an optical thickness of approximately $0.5 \mu \mathrm{m}$. After choosing the field, cells were submitted to $543 \mathrm{~nm}$ and $488 \mathrm{~nm}$ laser scanning. Images were obtained through on-line computation and sliced into 20-25 sections. Single confocal optical slices near the middle of the infected cells were analysed with the ZEISS LSM Image Browser Version 3,2,0,115 Program (Carl Zeiss GmbH, Germany).

Epon inclusion and thin sections of infected HEK 293 cells - Monolayers of HEK 293 cells were prepared in 25 $\mathrm{cm}^{2}$ vessels. After two days, when the culture confluence reached $70 \%$, cells were washed with PBS-A and the cultures were inoculated with purified $0.04 \mathrm{MOI}$ of HAdV41. After an adsorption period of $1 \mathrm{~h}$ at $37^{\circ} \mathrm{C}$, each culture was filled with EMEM containing $0.2 \% \mathrm{FBS}$ and the cells were incubated at $37^{\circ} \mathrm{C}$ in a $5 \% \mathrm{CO}_{2}$ atmosphere.

After $72 \mathrm{~h}$ and $156 \mathrm{~h}$ post-infection (p.i.), corresponding to the medium and final point of the infection kinetic, the cells were recovered and fixed with $2.5 \%$ glutaraldehyde in a $100 \mathrm{mM}$ HEPES buffer (pH 7.4), post-fixed with $1 \%$ osmium tetraoxide and dehydrated with ethanol. Ultra-thin sections $(80 \mathrm{~nm})$ of infected cells embedded in Epon were produced and collected on carbon-coated grids. Grids were stained first with saturated uranyl acetate in $50 \%$ ethanol and then with $1 \mathrm{M}$ lead citrate. Observations were made with a Philips CM12 transmission electronic microscope (TEM, Philips, Eindhoven, Netherlands).

\section{RESULTS}

Purified HAdV-2 and HAdV-41 titration by IIF HAdV-41 was efficiently propagated in HEK 293 cells and purified with a $\mathrm{CsCl}$ gradient. Titres obtained were $1.1 \times 10^{7} \mathrm{FFU} / \mathrm{mL}$ for HAdV-41 and $2.2 \times 10^{8} \mathrm{FFU} / \mathrm{mL}$ for the HAdV-2. By analysing the purified HAdV-41 with TEM, it was possible to observe a large number of complete viral particles (Fig. 1, micrograph A). The zoomed image shows long and short fibres distributed in distinct vertices of HAdV-41 (Fig. 1, micrograph B, indicated with arrows).

HAdV-41 and HAdV-2 infection kinetics assay - At $24 \mathrm{~h}$ p.i., a few of the cells infected with HAdV-41 presented a discrete intracellular cytoplasm fluorescence (Fig. 2A), which increased from 48 h-60 h p.i. The intensity of the cytoplasmic fluorescence was higher in cells infected with HAdV-2 (Fig. 2B). At 36 h p.i., cells infected with HAdV-2 showed cytoplasmic fluorescence and a large spread of viral proteins into the intercellular space, in a radial gradient emanating from the infected cell to neighbour cells and showing more intense fluorescence at the cell junctions (Fig. 3A-D).

At $60 \mathrm{~h}$ p.i., cells infected with HAdV-41 showed intense cytoplasmic fluorescence with inclusion bod-
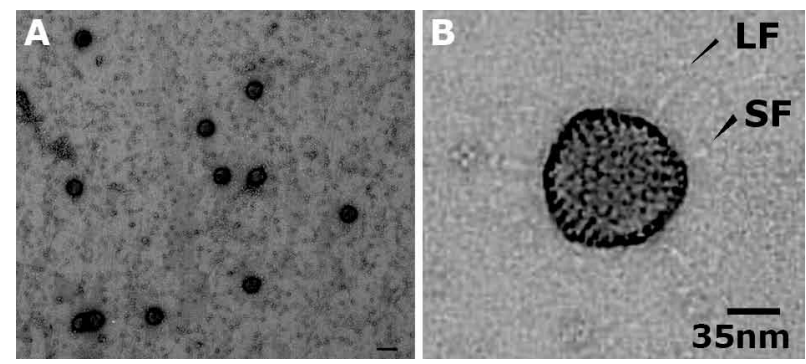

Fig. 1: transmission electronic microscope of HAdV-41 (Tak strain). The virus was produced in 293 cells, purified in a $\mathrm{CsCl}$ gradient and negatively stained with uranil acetate. A: the presence of HAdV-41 on carbon (magnification: 15,000 X; Bar $=100 \mathrm{~nm}$ ) B: the zoom shows long and short fibers attached to different bases in the HAdV-41 (by arrows). $\mathrm{Bar}=35 \mathrm{~nm}$.
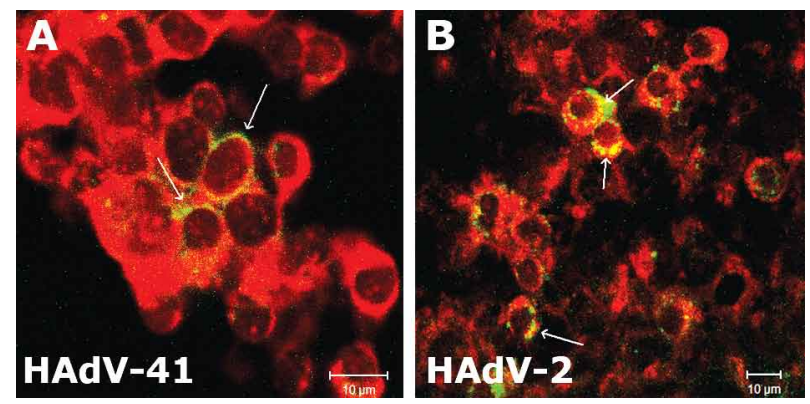

Fig. 2: kinetics of HAdV-41 and HAdV-2 infection in 293 cells. Newly synthesized viral proteins in the cytoplasm of infected cells (indicated by arrows) at $24 \mathrm{~h}$ of infection, revealed with rabbit polyclonal antiserum to HAdV-41 (A) and rabbit polyclonal antiserum to HAdV-5 (B). $\mathrm{Bar}=10 \mu \mathrm{m}$. 
ies (Fig. 4A, B) and a large spread of viral proteins into the intercellular space (Fig. 5A-D). Cells infected with HAdV-2, in contrast, showed nuclear fluorescence and nuclear inclusion bodies (Fig. 4C, D), as well as viral proteins in the cytoplasm. At this time point, the integrity of the HAdV-2 infected cells was still maintained.

At 72 h p.i., HAdV-41-infected cells showed nuclear fluorescence, as shown in the orthogonal projection of the image (Fig. 6A). The nuclear inclusion bodies became more evident after TEM analysis (Fig. 6 , micrograph B). Cells infected with HAdV-2 were lysed and a new infectious cycle had begun all around the culture monolayer, with cells showing fluorescent cytoplasms (data not shown).

At $84 \mathrm{~h}$ p.i., cells infected with HAdV-41 showed granular cytoplasmic fluorescence and a discrete spreading of viral proteins or viruses to the surrounding environment (Fig. 7A). Different stages of infection were observed in cells infected with HAdV-2, including granular cytoplasmic or nuclear fluorescence, cell detachment from the coverslip surface and cell lysis (Fig. 7B).

During kinetics experiments, HEK 293 cells used as a negative control were collected every day. In Fig. $7 \mathrm{C}$, a control cell collected after $84 \mathrm{~h}$ of incubation is shown. Cell integrity and the absence of fluorescence could be observed until $120 \mathrm{~h}$. After this time, both cell monolayer retraction and cell cluster formation were observed due to the high density of cells reached after the long period of cultivation.

At $96 \mathrm{~h}$ p.i., a discrete spreading of viral proteins or viruses was observed in cells infected with HAdV-41. Most of the cells showed granular cytoplasmic fluores-
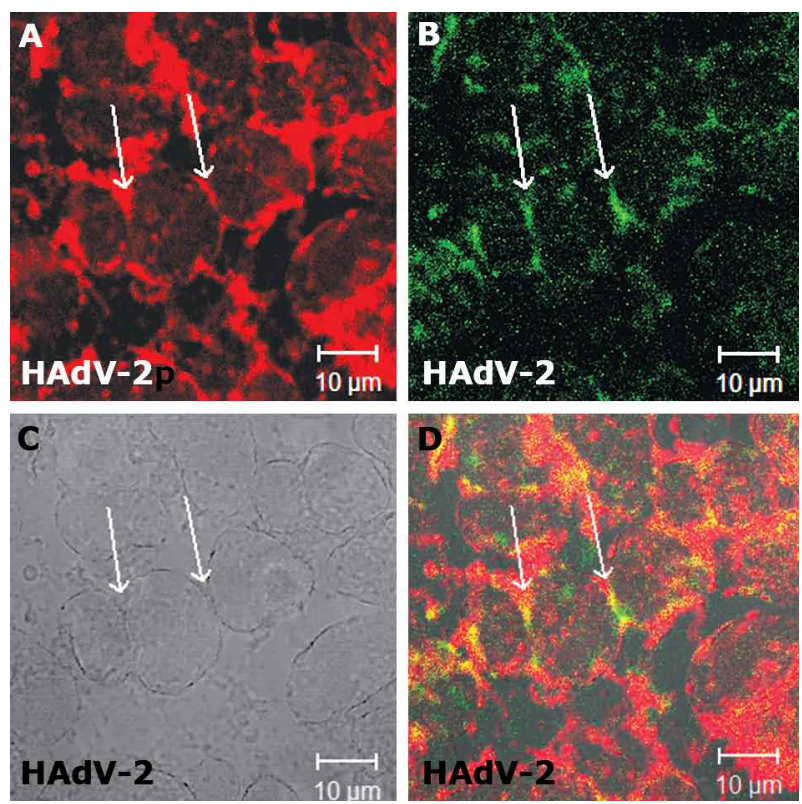

Fig. 3: kinetics of HAdV-2 infection in 293 cells. Newly synthesized viral proteins revealed at $36 \mathrm{~h}$ of infection. A: 293 cells stained with Evan's Blue; B: viral proteins in extra-cellular space revealed with rabbit polyclonal antiserum anti HAdV-5; C: Nomarsky microscopy; D: merged images. Arrows indicate cell-junction regions. Bar $=10 \mu \mathrm{m}$.
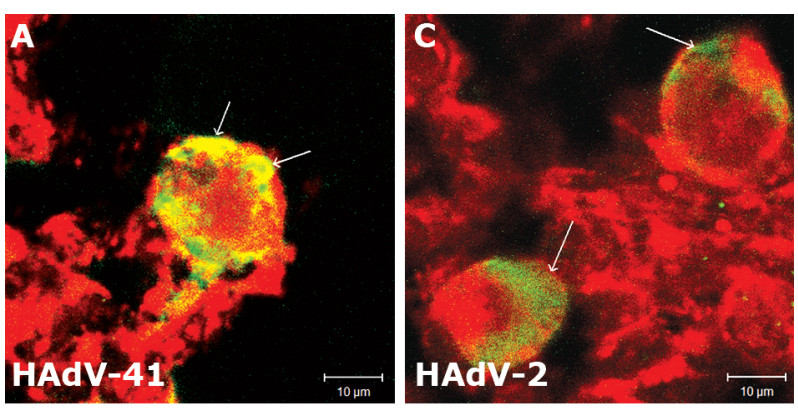

$\mathbf{B}$

D

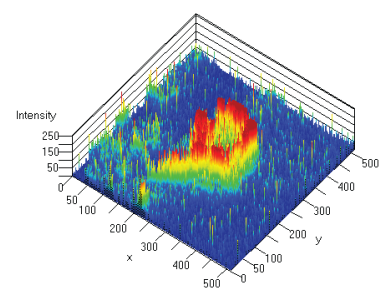

HAdV-41

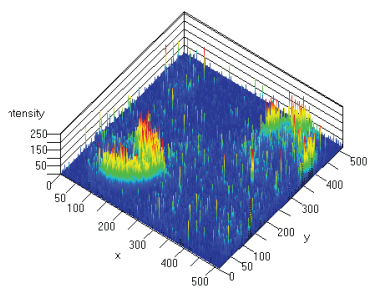

HAdV-2

Fig. 4: kinetics of HAdV-41 and HAdV-2 infection in 293 cells at $60 \mathrm{~h}$ of infection. A: newly synthesized HAdV-41 proteins in the cytoplasm of an infected cell (arrows indicate inclusion bodies); B: graphic representation of fluorescence intensity; C: newly formed HAdV-2 in the nucleus of infected cells (nuclear inclusion bodies indicated by arrows); D: graphic representation of observed fluorescence intensity. Bar $=10 \mu \mathrm{m}$.

cence (data not shown). At this time, it was possible to observe an isolated cell infected with HAdV-2 undergoing lysis and presenting an extruding cytosol with the release of viral particles into the extracellular space (indicated by arrow, Fig. 8A-D).

After $132 \mathrm{~h}$ p.i., nuclear inclusion bodies became more evident in cells infected with HAdV-41 (Fig. 9A). The infection had spread to neighbouring cells by 144 h p.i. and at 156 h p.i. (Fig. 9B, C), it was possible to observe foci of infected cells with strong cytoplasmic or nuclear fluorescence. Retraction of the cell monolayer and the formation of clusters of infected cells detaching from the poly-D-lysine matrix were then observed. After $156 \mathrm{~h}$, it was possible to observe the hexagonal arrangement of viral particles and the release of new viral progeny from the nucleus (Fig. 10, indicated by arrows).

At 168 h p.i. (Fig. 11A-D), it was possible to observe a cell with granular cytoplasmic fluorescence apparently overlapping the cell monolayer (Fig. 11D) as well as the release of viral proteins or virus particles to the nearest cells (Fig. 11B). This phenomenon was also observed in other areas of the culture with detached clusters of infected cells overlapping the culture and giving rise to new foci of infection.

Intense fluorescence was observed throughout the cell monolayer at $180 \mathrm{~h}$ p.i. (Fig. 11E), indicating that by then almost all of the cells were infected. Strong retraction of the cell monolayer and detachment of infected cell clusters could be observed. Even after seven days of infection, lysis was not observed in cells infected with HAdV-41. 

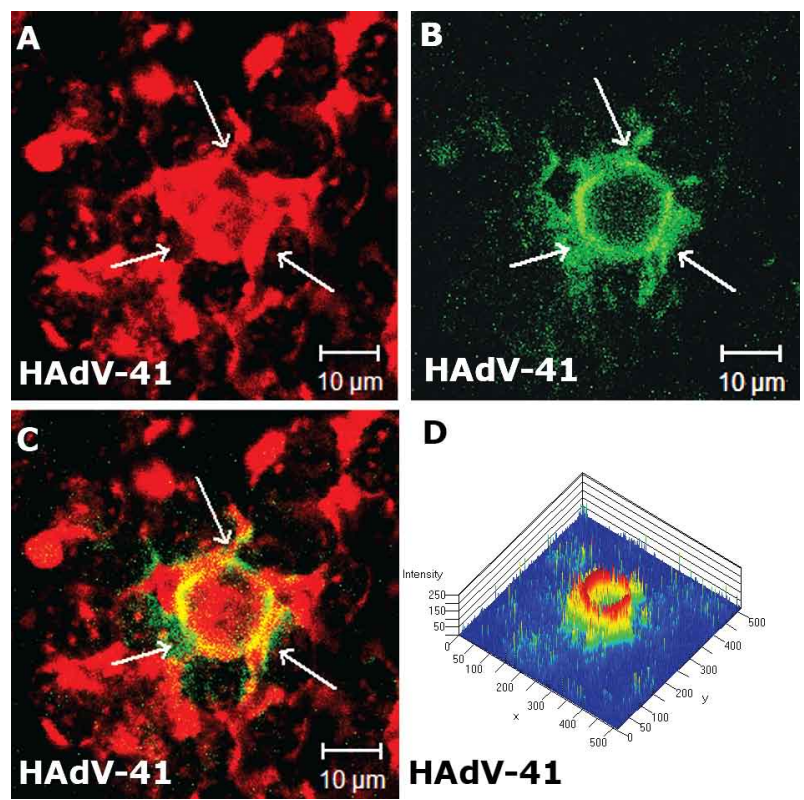

D

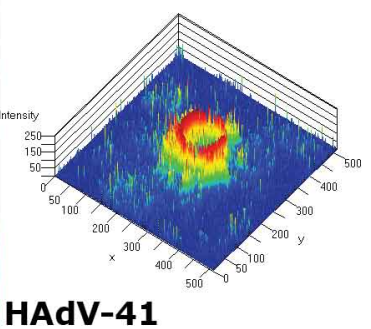

Fig. 5: HAdV-41 multiplication in 293 cells at $60 \mathrm{~h}$ of infection. Visualization of viral proteins spread to extra-cellular space (A) 293 cells stained with Evan's blue. B: viral proteins in extracellular space revealed with rabbit polyclonal antiserum to HAdV-41; C: merged images; D: graphic representation of fluorescence intensity. Arrows indicate viral proteins outside the cell. Bar $=10 \mu \mathrm{m}$.

\section{DISCUSSION}

There are three good reasons for studying the species F human adenoviruses (HAdV-40 and HAdV-41). First, they are important etiological agents of infantile gastroenteritis (de Jong et al. 1983, Uhnoo et al. 1984, Kidd et al. 1986). Second, adenoviruses may take advantage of an impaired or destroyed immune system to set up persistent or generalised infections in an immune-compromised host (Hierholzer 1992). Third, they have been proposed as gene transfer vectors for intestinal epithelial cells (Croyle et al. 1998) and as vaccine vectors (Lemiale et al. 2007).
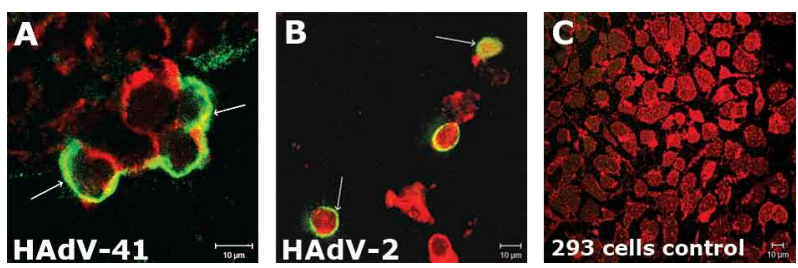

Fig. 7: HAdV-2 and HAdV-41 infection in 293 cells at $84 \mathrm{~h}$ of infection. A: HAdV-41 shows evident cytoplasm fluorescence in cluster of infected cells; B: HAdV-2 infected cells with fluorescent cytoplasm or nucleus (arrows) and extensive destruction of cell monolayer by lysis. $\mathrm{C}$ : monolayer of control cells with preserved cells integrity. Bar $=10 \mu \mathrm{m}$.

The aim of this work was to obtain an overview of the infectious cycle of HAdV-41 and to compare that cycle to that of the Human adenovirus C prototype, HAdV-2, the best understood adenovirus. For the development of such a study, large amounts of purified viruses were required. HAdV-41 is known to grow feebly under laboratory conditions and an improved protocol for its purification therefore had to be developed. The cells were split with trypsin without EDTA. To improve virus attachment, the cell monolayers were washed with PBS-A before inoculation. Virus stocks were inoculated with a low MOI to avoid cell detachment prior to viral production. Infected cells were maintained in EMEM medium with $0.2 \%$ FBS. Viruses were recovered just before spontaneous cell detachment (between 5-7 days). Finally, viruses were extracted from large amounts of infected cells and $\mathrm{CsCl}$ purification was preceded by clarification with Vertrel-XF (Clarus Technology ${ }^{\circledR}$ ) to promote the removal of membranes. Titres of the recovered HAdV-41 infectious particles were approximately 20 times lower than that of HAdV-2. Although this seems to be a low ratio, it is higher than those obtained with other methods previously used to produce HAdV-41 (Brown 1985). In a recent study using HAdV-41 as a vaccine vector, the efficient rescue of infectious particles, obtained after transfection of HEK 293-ORF6 cells with purified DNA, was 100 times lower than that of the HAdV-5 vector (Lemiale et al. 2007). Our
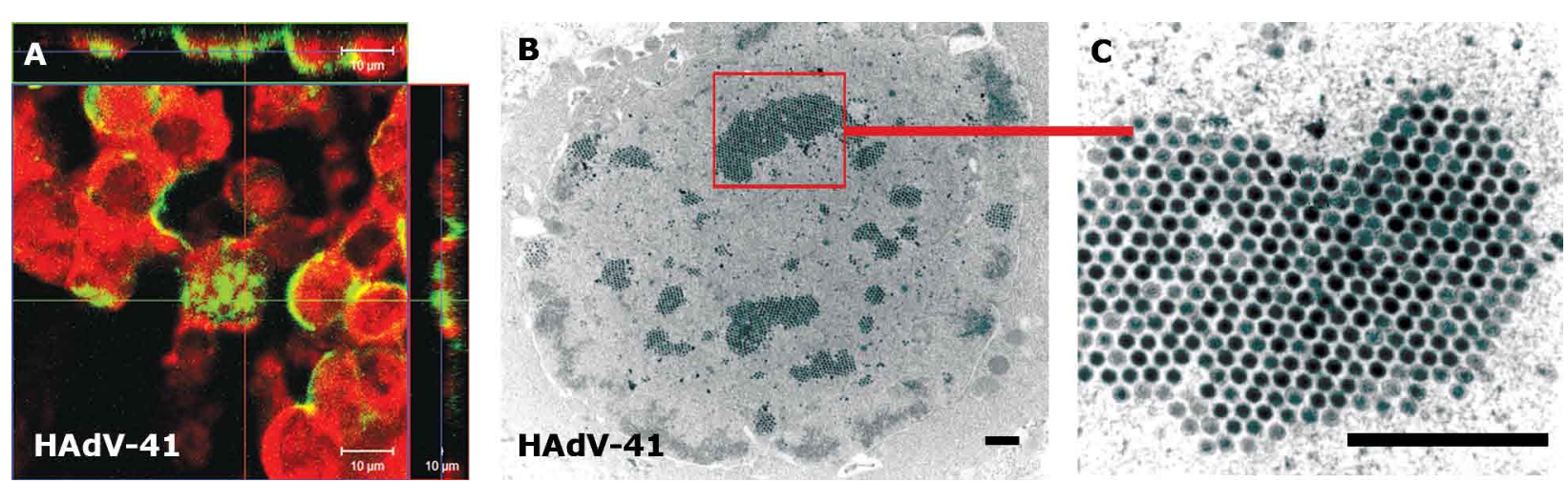

Fig. 6: HAdV-41 multiplication in 293 cells at $72 \mathrm{~h}$ of infection. A: intra-nuclear inclusion bodies revealed on orthogonal projection of $\mathrm{x}$ and $\mathrm{y}$ axes. Bar $=10 \mu \mathrm{m}$; B: representative transmission electronic microscope section of HAdV-41 infected cell showing paracrystalline arrays of adenovirus particles in the nucleus $(\mathrm{Bar}=1 \mu \mathrm{m})$; $\mathrm{C}$ : zoom shows paracrystalline arrays of adenovirus particles $(\mathrm{Bar}=1 \mu \mathrm{m})$. 

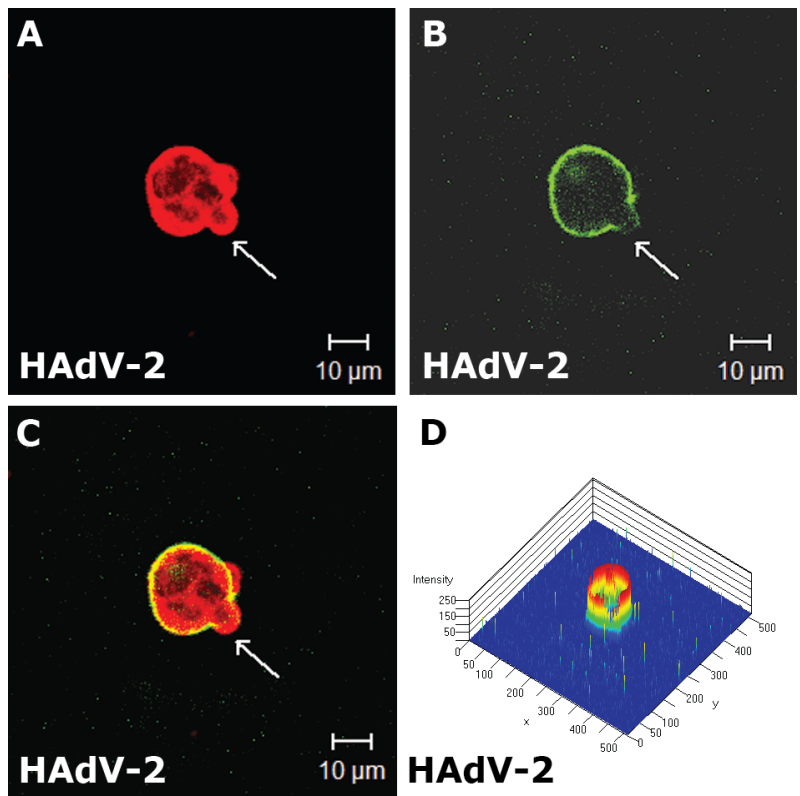

Fig. 8: HAdV-2 multiplication in 293 cells at $96 \mathrm{~h}$ of infection. A: infected cell lyses with extrusion of the cytoplasm (arrows), 293 cells stained with Evan's blue; B: viral proteins revealed with polyclonal antiserum; C: merged images; D: graphical representation of fluorescence intensity. Bar $=10 \mu \mathrm{m}$.
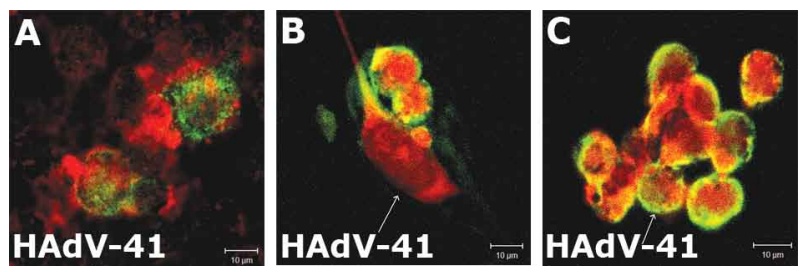

Fig. 9: kinetics of HAdV-41 infection in 293 cells. A: at $132 \mathrm{~h}$ of infection, cells with the presence of nuclear inclusion bodies and the absence of lysis. B, C: at $144 \mathrm{~h}$ and $156 \mathrm{~h}$ of infection, respectively, cell clusters rounding and detaching from the surface (arrows). Bar $=10 \mu \mathrm{m}$.

results show that it is possible to obtain good titres of infectious HAdV-41, with the recovery of complete viral particles (as shown by electron microscopy), when the culture conditions described above are used and enough time is given to complete the virus multiplication cycle.

A polyclonal rabbit anti-HAdV-5 antibody produced in the laboratory for another study (Peret et al. 1995) proved to be very useful for revealing HAdV-2 proteins in infected cells. These two serotypes belong to the same species and are known to cross-react in serology. In contrast, when this serum was applied to cells infected with HAdV-41, a non-satisfactory result was obtained. Therefore, we prepared a polyclonal serum in a rabbit inoculated with purified HAdV-41. The serum obtained gave good titres and was successfully used in the kinetics study. The monoclonal antibodies to HAdV-41 (hexon protein) worked well when titring the virus by ELISA, but gave poor results in immunofluorescence studies.

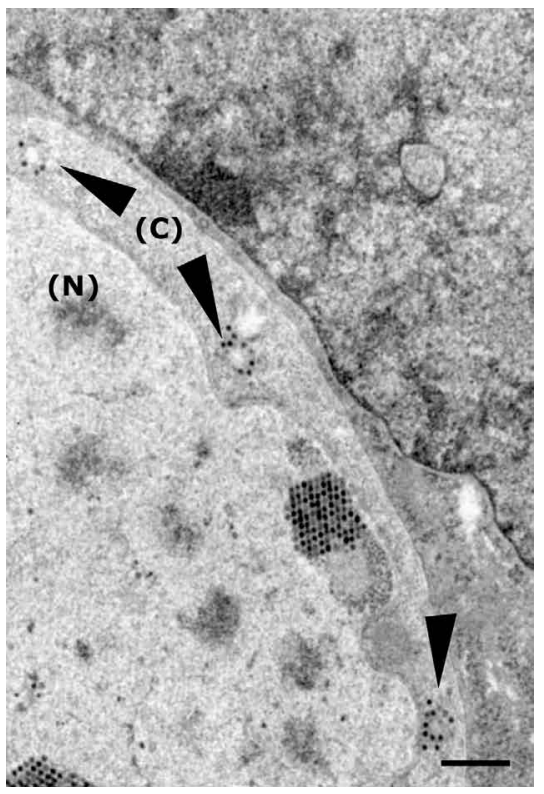

Fig. 10: kinetics of HAdV-41 infection in 293 cells. After $156 \mathrm{~h}$ of infection, a representative section through one cell infected with HAdV-41, showing paracrystalline arrays of adenovirus particles in the nucleus and virus particles released into the cytoplasm (arrows). $\mathrm{Bar}=1 \mu \mathrm{m}$.

For the kinetics assays, a low MOI (0.04) was used for both viruses. The main reason for choosing such a low MOI was the fact that one of the receptors used by adenoviruses, CAR, is a cell adhesion molecule and a component of the tight-junctions. At the beginning of the viral multiplication cycle, a large amount of pentons (bases and fibres) is released from the infected cells (Walters et al. 2002). It is known that in infections with a high MOI of adenoviruses, the excess of pentons causes a cytotoxic effect with rapid destruction of the cell monolayer. As a consequence, analyses of the virus infection kinetics would not be possible. Cells infected with a low MOI made it possible to carefully observe the spread of the infection to neighbouring cells.

The HEK 293 cells were infected with the same MOI of HAdV-41 and HAdV-2. At $24 \mathrm{~h}$, cultures infected with HAdV-41 showed a few cells with a granular fluorescent cytoplasm and discrete intercellular fluorescence. The fluorescence increased in intensity through the $48 \mathrm{~h}$ time point. At $60 \mathrm{~h}$, infected cells presented intense cytoplasmic fluorescence with inclusion bodies and a large spread of viral protein in the intercellular space, in a radial gradient emanating from the infected cell to neighbouring cells. This process was delayed $24-30 \mathrm{~h}$ relative to that of HAdV-2. The spreading of HAdV-41 viral proteins into the extracellular milieu, visualised with a polyclonal anti-serum, showed the same pattern as observed by Trotman et al. (2003) for an HAdV-2 infection in A549 cells (human lung carcinoma), visualised with monoclonal antibodies to penton-base. Although there are known differences in the HAdV-41 penton-base and fibre sequences (Kidd et al. 1990), likely resulting in the 

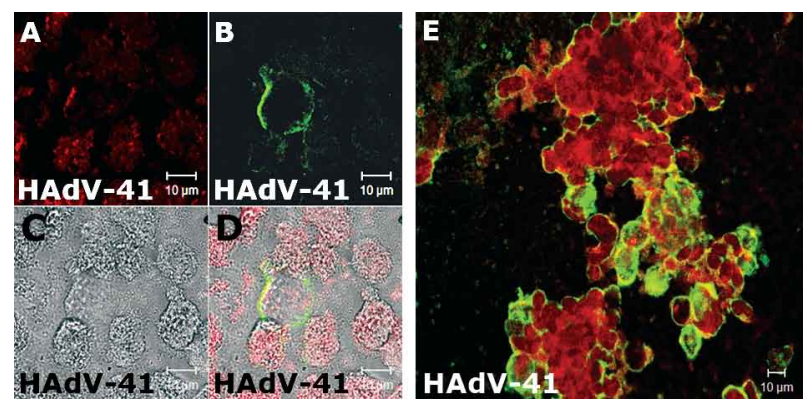

Fig. 11: kinetics of HAdV-41 infection in 293 cells. At $168 \mathrm{~h}$ of infection, the view of an infected cell that had detached from the monolayer, attached in another part of the culture and released viral proteins or particles. A: 293 cells stained with Evan's blue; B: an infected cell overlapping the culture monolayer, viral proteins revealed with rabbit polyclonal antiserum anti HAdV-41; C: Nomarsky microscopy; D: merged images; E: at $180 \mathrm{~h}$ of infection, all cells of the culture present either fluorescent cytoplasm or nuclei. Clusters of infected cells detaching from the monolayer. Bar $=10 \mu \mathrm{m}$.

recognition of different receptors (Albinsson \& Kidd 1999), these proteins were shown to be exported in the same manner as HAdV-2 pentons, possibly through a Golgi-independent mechanism (Trotman et al. 2003).

At the beginning of the infection cycle, before the assembly of viral progeny (from 30-60 h), an excess of penton-bases and fibres are released from the infected cells and these proteins interact with receptors such as CAR, integrins and also with heparan-sulfate in the intercellular space. Early release of penton-bases and fibres will dissociate cell junctions and possibly prepare surrounding cells for infection (Walters et al. 2002). This might be an important strategy of this virus to to make permeable the gut columnar epithelia and facilitate viral spreading.

The HAdV-41 multiplication cycle had a slower progression than that of HAdV-2. Newly produced viral particles accumulated inside the cell nucleus from $72-132 \mathrm{~h}$ p.i. Viral progeny were then released from the infected cells into neighbouring cells, showing a focal dispersion of the infection. To observe whether newly produced viruses pass from cell to cell or are released into the extracellular space, infectivity experiments were repeated with the addition of a neutralising serum to the culture medium at $72 \mathrm{~h}$ p.i. (data not shown). These antibodies partially reduced viral spreading, suggesting that HAdV41 progeny are liberated from the host cell through a nonlytic and likely non-Golgi-dependent, unknown mechanism. In contrast, HAdV-2 caused lysis, with subsequent infection of the whole cell culture, as previously described (Tollefson et al. 1996b, 2003). The efficient release of HAdV-2 virus in the lytic cycle occurs due to the adenovirus death protein (ADP). This protein is exclusively present in Human adenovirus $C$ and is expressed by the 11.6K ORF of the E3 region (Tollefson et al. 1996a, b). All of the other human adenovirus species lack this ORF. HAdV-41 does not express ADP and consequently does not lyse infected cells. In this study, it was observed that with the progression of the HAdV-41 infection, groups of cells retracted, lost adhesion and detached from the ma- trix. These groups of infected cells then attached to other parts of the cell monolayer, undergoing a gradient release of viral particles and giving rise to new foci of infected cells. Similar results were observed previously (Brown et al. 1992) in HEK 293 cultures experimentally seeded with clusters of infected HeLa or HEK 293 cells. HAdV41 viral particles were released from HEK 293 cells, but not from HeLa cells and initiated new foci of infection. These results reinforce the hypothesis that this virus may have an active mechanism of viral release and that this could be more efficient in certain cell lines. The block on viral release was also observed in experimental infection of foetal intestinal organ cultures, suggesting an adaptation of HAdV-41 to epithelia that turn over rapidly (Tiemessen et al. 1993). It is also possible that the release of viral particles may be dependent upon the presence of proteolytic enzymes and low $\mathrm{pH}$, which are present in the gut but not in culture. The pathology of species $\mathrm{F}$ adenovirus enteritis may not be dependent on growth capabilities or on tissue damage but rather on the ability of this virus to avoid immune surveillance upon infection and establish persistent or prolonged infection.

The results obtained in this work show the progression of HAdV-41 infection in HEK 293 cells and give support for the use of this virus in the development of vaccine and gene therapy vectors. These results may also be used as a reference for the study of this virus infectivity in other cell lines, such as intestinal or lymphocytic cells, in order to better understand the biology of this virus.

\section{ACKNOWLEDGMENTS}

To Dr. Gláucia Maria Machado-Santelli and M. Roberto Cabado, from the Department of Cell Biology and Development of the Institute of Biomedical Sciences, for the technical assistance and concession to use the CLSM, to Patricia O. Moura, M. Bs. Sc., for technical assistance with cell and virus cultivation, to Daphna Fenel, from Laboratoire de Microscopie Electronique Structurale, for technical assistance with the TEM, and to Gábor Dömötör, for the English revision.

\section{REFERENCES}

Albinsson B, Kidd AH 1999. Adenovirus type 41 lacks an RGD alpha (v) integrin binding motif on the penton base and undergoes delayed uptake in A549 cells. Virus Res 64: 125-136.

Bergelson JM 1999. Receptors mediating adenovirus attachment and internalization. Biochem Pharmacol 57: 975-979.

Bergelson JM, Cunnigham JA, Droquet G, Kurt-Jones EA, Krithivas A, Hong JS, Horwitz MS, Crowell RL, Finberg RW 1997. Isolation of a common receptor for coxsackie B viruses and adenoviruses 2 and 5. Science 275: 1320-1323.

Brown M 1985. Selection of nonfastidious adenovirus species in 293 cells inoculated with stool specimens containing adenovirus 40 . J Clin Microbiol 22: 205-209.

Brown M, Petric M 1986. Evaluation of cell line 293 for virus isolation in routine viral diagnosis. J Clin Microbiol 23: 704-708.

Brown M, Petric M, Middleton PJ 1984. Diagnosis of fastidious enteric adenoviruses 40 and 41 in stool specimens. J Clin Microbiol 20: $334-338$.

Brown M, Wilson-Friesen HL, Doane F 1992. A block in release of progeny virus and a high particle-to-infectious unit ratio contribute to poor growth of enteric adenovirus types 40 and 41 in cell culture. J Virol 66: 3198-3205. 
Chiba S, Nakata S, Nakamura I, Taniguchi K, Urasawa S, Fujinaga K, Nakao T 1983. Outbreak of infantile gastroenteritis due to type 40 adenovirus. Lancet 2: 954-957.

Coyne CB, Bergelson JM 2005. CAR: a virus receptor within the tight junction. Adv Drug Deliv Rev 57: 869-872.

Croyle MA, Stone M, Amidon GL, Roessler BJ 1998. In vitro and in vivo assessment of adenovirus 41 as a vector for gene delivery to the intestine. Gene Ther 5: 645-654.

Cusack S 2005. Adenovirus complex structures. Curr Opin Struct Biol 15: 237-243.

de Jong JC, Wigand R, Kidd AH, Wadell G, Kapsenberg JG, Muzerie CJ, Wermenbol AG, Firtzlaff RG 1983. Candidate adenoviruses 40 and 41: fastidious adenoviruses from human infant stool. J Med Virol 11: 215-231.

Favier AL, Schoehn G, Jaquinod M, Hársi CM, Chroboczek J 2002. Structural studies of human enteric adenovirus type 41. Virology 293: $75-85$.

Gaggar A, Shayakhmetov DM, Lieber A 2003. CD46 is a cellular receptor for group B adenoviruses. Nat Med 9: 1408-1412.

Graham FL, Smiley J, Russell WC, Nairn R 1977. Characteristics of a human cell line transformed by DNA from human adenovirus type 5. J Gen Virol 36: 59-72.

Greber UF, Suomalainen M, Stidwill RP, Bouck K, Ebersold MW, Helenius A 1997. The role of the nuclear pore complex in adenovirus DNA entry. EMBO 16: 5998-6007.

Greber UF, Willets M, Webster P, Helenius A 1993. Stepwise dismantling of adenovirus 2 during entry into cells. Cell 75: 477-486.

Hierholzer JC 1992. Adenoviruses in the immunocompromised host. Clin Microbiol Rev 5: 262-274.

Kanegae Y, Makimura M, Saito I 1994. A simple and efficient method for purification of infectious recombinant adenovirus. Jpn J Med Sci Biol 47: 157-166.

Kidd AH, Chroboczek J, Cusack S, Ruigrok RW 1993. Adenovirus type 40 virions contain two distinct fibers. Virology 192: 73-84.

Kidd AH, Erasmus MJ, Tiemessen CT 1990. Fiber sequence heterogeneity in subgroup F adenoviruses. Virology 179: 139-150.

Kidd AH, Madeley CR 1981. In vitro growth of some fastidious adenoviruses from stool specimens. J Clin Pathol 34: 213-216.

Kidd AH, Rosenblatt A, Besselaar TG, Erasmus MJ, Tiemessen CT, Berkowitz FE, Schoub BD 1986. Characterization of rotaviruses and subgroup $\mathrm{F}$ adenoviruses from acute summer gastroenteritis in South Africa. J Med Virol 18: 159-168.

Lemiale F, Haddada H, Nabel GJ, Brough DE, King CR, Gall JG 2007. Novel adenovirus vaccine vectors based on the enteric-tropic serotype 41. Vaccine 25: 2074-2084.

Mathias P, Wickham T, Moore M, Nemerow G 1994. Multiple adenovirus serotypes use alpha $\mathrm{v}$ integrins for infection. $J$ Virol 68: 6811-6814.

Mautner V 2007. Growth and purification of enteric adenovirus type 40. Methods Mol Med 130: 145-156.

Mautner V, Mackay N, Steinthorsdottir V 1989. Complementation of enteric adenovirus type 40 for lytic growth in tissue culture by E1B $55 \mathrm{~K}$ function of adenovirus types 5 and 12 . Virology 171: 619-622.

Meier O, Greber UF 2003. Adenovirus endocytosis. J Gene Med 5: 451-462.

Miyazawa N, Crystal RG, Leopold PL 2001. Adenovirus serotype 7 retention in a late compartment prior to cytosol escape is modulated by fiber protein. $J$ Virol 75: 1387-1400.
Miyazawa N, Leopold PL, Hackett NR, Ferris B, Worgall S, FalckPedersen E, Crystal RG 1999. Fiber swap between adenovirus subgroups $\mathrm{B}$ and $\mathrm{C}$ alters intracellular trafficking of adenovirus gene transfer vectors. $J$ Virol 73: 6056-6065.

Peret TC, Durigon EL, Candeias JM, Stewien KE, Candeias JA 1995. A combined staphylococcal coagglutination assay for rapid identification of rotavirus and adenovirus (COARA). $J$ Virol Meth 52: $265-272$.

Pieniazek D, Pieniazek NJ, Macejak D, Lufting RB 1990. Enteric adenovirus 41 (Tak) requires low serum for growth in human primary cells. Virology 178: 72-80.

Pieniazek NJ, Slemenda SB, Pieniazek D, Velarde J Jr, Lufting RB 1990. Human enteric adenovirus type 41 (Tak) contains a second fiber protein gene. Nucl Acids Res 18: 1901.

Roelvink PW, Lizonova A, Lee JG, Li Y, Bergelson JM, Finberg RW, Brough DE, Kovesdi I, Wickham TJ 1998. The coxsackievirusadenovirus receptor protein can function as a cellular attachment protein for adenovirus serotypes from subgroups A, C, D, E and F. J Virol 72: 7909-7915.

Short JJ, Vasu C, Holterman MJ, Curiel DT, Pereboev A 2006. Members of adenovirus species B utilize CD80 and CD86 as cellular attachment receptors. Virus Res 122: 144-153.

Takiff HE, Straus SE, Garon CF 1981. Propagation and in vitro studies of previously non-cultivable enteral adenoviruses in 293 cells. Lancet 2: 832-834.

Tiemessen CT, Kidd AH 1990. Adenovirus 41 growth in semi-permissive cells shows multiple-hit kinetics. Arch Virol 110: 239-245.

Tiemessen CT, Ujfalusi M, Kidd AH 1993. Subgroup F adenovirus growth in foetal intestinal organ cultures. Arch Virol 132: $193-200$

Tollefson AE, Ryerse JS, Scaria A, Hermiston TW, Wold WS 1996a. The E3-11.6-kDa adenovirus death protein (ADP) is required for efficient cell death: characterization of cells infected with ADP mutants. Virology 220: 152-162.

Tollefson AE, Scaria A, Hermiston TW, Ryerse JS, Wold LJ, Wold WS 1996b. The adenovirus death protein (E3-11.6K) is required at very late stages of infection for efficient cell lysis and release of adenovirus from infected cells. $J$ Virol 70: 2296-2306.

Tollefson AE, Scaria A, Ying B, Wold WS 2003. Mutations within the ADP (E3-11.6K) protein alter processing and localization of ADP and the kinetics of cell lysis of adenovirus-infected cells. J Virol 77: 7764-7778.

Trotman LC, Achermann DP, Keller S, Straub M, Greber UF 2003. Non-classical export of an adenovirus structural protein. Traffic 4: 390-402.

Uhnoo I, Wadell G, Svensson L, Johansson M 1983. Two new serotypes of enteric adenovirus causing infantile diarrhoea. Dev Biol Stand 53: 311-318.

Uhnoo I, Wadell G, Svensson L, Johansson ME 1984. Importance of enteric adenoviruses 40 and 41 in acute gastroenteritis in infants and young children. J Clin Microbiol 20: 365-372.

Walters R, Freimuth P, Moninger TO, Ganske I, Zabner A, Welsh M 2002. Adenovirus fiber disrupts CAR-Mediated intercellular adhesion allowing virus escape. Cell 110: 789-799.

Wickham TJ, Filardo EJ, Cheresh DA, Nemerow GR 1994. Integrin alpha $\mathrm{v}$ beta 5 selectively promotes adenovirus mediated cell membrane permeabilization. J Cell Biol 127: 257-264.

Witt DJ, Bousquet EB 1988. Comparison of enteric adenovirus infection in various human cell line. $J$ Virol Meth 20: 295-308.

Wood DJ, de Jong JC, Bijlsmak K, Van der Avoort HG 1989. Development and evaluation of monoclonal antibody-based immune electron microscopy for diagnosis of adenovirus types 40 and 41 . $J$ Virol Meth 25: 241-250. 